The Canadian Journal of Higher Education, Vol. XXIV-2, 1994

La revue canadienne d'enseignement supérieur, Vol. XXIV-2, 1994

\title{
An Evaluation of Pay Equity Reports at Five Canadian Universities*
}

\author{
JAMES M. DEAN ${ }^{\dagger} \&$ RODNEY A. CLIFTON ${ }^{\dagger}$
}

\begin{abstract}
This paper reviews five reports measuring discrimination in salaries between males and females at Canadian universities. All find some discrimination (3\% to $8 \%$ ), a result in accord with published research on the same topic. However, the approaches taken are quite different, often reflecting controversial decisions over which variables would be included to explain salary differentials. We examine the strengths and weaknesses of these reports. In particular, the focus on single equation models is a problem since some of the controversial variables, which may be biased by discrimination, also contain some information which explains legitimate differences in salaries. Our review suggests that many of the models are probably misspecified. We conclude with a call for universities to collect the information which is required to complete these studies expeditiously and accurately.
\end{abstract}

\section{Résumé}

Ce article fait l'examen de cinq rapports portant sur l'équité salariale dans les universités canadiennes. Tous les rapports documentent l'existence d'écarts salariaux (entre 3 et 8\%) qui reflètent les écarts généralement recensés dans les écrits sur le sujet. Cependant, ces résultats reposent sur des approches méthodologiques très différentes qui témoignent de décisions controversées

* The authors thank Derek Hum, Wayne Simpson and three anonymous referees for helpful comments on a previous draft.

$\dagger$ University of Manitoba 
ayant trait à la sélection des variables pouvant expliquer les écarts salariaux. L'étude analyse les forces et les faiblesses des approches utilisées. En particulier, le choix de modèles à une seule équation pose problème puisque certaines variables sélectionnées peuvent à la fois décrire des différences salariales discriminatoires et contenir de l'information permettant d'expliquer des écarts légitimes de salaires. Notre analyse suggère donc que plusieurs modèles ne permettent pas d'expliquer adéquatement les écarts salariaux et que. les universités concernées devraient rapidement faire la collecte d'informations supplémentaires pertinentes pour compléter les études déjà réalisées.

\section{Introduction}

This paper is an evaluation of pay equity studies in Canadian universities. Pay equity is interpreted as the concern that faculty associations, administrators, and faculty members have with ensuring that females are paid equally to males with comparable qualifications and experiences. There appears to be a consensus among these various groups that pay equity is an important goal to be sought, and a priority among the competing demands for discretionary funds that are available.

A number of universities have attempted to identify the existence and size of the inequities in salaries between male and female faculty members. Studies from a few universities have been published, but the majority of studies have not, and they are often unavailable to other researchers. This is unfortunate since the unpublished studies reveal a great variation in how they estimate the size of pay inequities. In this paper, we examine five recent reports on pay equity from Canadian universities. In each study, the goal was the same, but the methods of calculating differences in salaries were different.

No doubt, it is reasonable to assume that legitimate differences in salaries can arise from differences among individuals and differences between groups. It is less clear what these legitimate differences are, and how they should be considered. On these two issues, the five reports vary considerably. Thus, we consider these reports in light of the published literature that evaluates the existence and magnitude of inequities in salaries. The published literature has shown that a number of factors other than gender (e.g., discipline, highest degrees, publications, and experience) explain some of the differences in salaries between male and female faculty members.

In the next section of this paper, the five reports are outlined, emphasizing the way the variables are measured and the way they are incorporated into the analytical models. In the third section, we analyse the reports and consider both 
their strengths and their weaknesses. This discussion focuses on the published literature and provides the framework for considering the five reports. Here, we also show that a number of value judgments have been made, and that people of good faith can often disagree on the adjustments that have been made in the salaries of particular faculty members. Finally, in the fourth section, we consider the implications of our analyses for future research on salary inequalities between male and female faculty members at Canadian universities.

\section{Five Reports on Pay Equity in Canadian Universities}

The five reports we review illustrate that there has been considerable effort to quantify inequalities in salaries between males and females at Canadian universities. The five reports vary in the approaches they have taken in estimating differences in salaries. The reports also vary in the variables that have been included and in the way that these variables have been measured. Nevertheless, there are a number of similarities between the reports. All the reports have been influenced by procedures outlined in a pay equity guide prepared for the Canadian Association of University Teachers (CAUT) by Allen (1984). In addition, all of the reports are based on multiple regression analyses. Finally, the quality of the research is more difficult to evaluate for internal reports than for published articles which have been subject to external review.

\section{Concordia University (1991)}

In 1989, Concordia University established a Joint Pay Equity Committee (JPEC). The JPEC recommended that multiple regression analyses should be used to assess differences in salaries between male and female academics. They advised that care should be taken in choosing the variables to include in the analyses and they quoted the CAUT report (Allen, 1984) that variables should satisfy three criteria before they should be included in the analyses. The variables should be credible; they should be legitimate determinants of salary; and they should not be correlated with discrimination. It was argued that the third criterion would exclude any variable that is plausibly affected by discrimination against females. As such, they decided that age was a legitimate variable but academic rank was not. The JPEC considered seniority to be the most important determinant of salaries and recommended the use of two seniority variables: maximum possible career length and minimum relevant career length. A variable was also included for the most appropriate terminal degree: Ph.D. in most faculties, and masters or professional degrees in others. After some discussion, the JPEC decided not to use productivity variables. As a test, however, they 
checked relationships between gender and special merit increases in every year since 1977. None of the correlations were statistically significant; thus the JPEC decided that special merit awards would not be used to explain differences in salaries between the genders. It was also argued that other productivity variables, publications and research grants received, for example, were not credible and consequently they were not included in the analyses. Only three variables, age, number of years since first full-time appointment, and highest degree (Ph.D. in most cases) were included in the analyses.

Three separate pairs of regression analyses were computed, one for each Faculty (Arts and Science, Commerce and Administration, and Fine Arts). Librarians were excluded from the analyses because of the small number of male librarians. The qualification variable was dropped from the regression for one faculty where the number of females was very small and all the females had Ph.D.s. Two regression analyses were examined for each of the three faculties, first to identify outliers, and second to assess gender differences when the outliers were excluded. In all analyses the number of outliers was small and had relatively small effects on the results. The final equations for Arts and Science Faculty explained $76.9 \%$ of the variance for female salaries and $64.1 \%$ of the variance for male salaries. The final equations for Commerce and Administration explained $44.2 \%$ of the variance for female salaries and $52.7 \%$

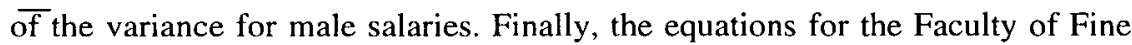
Arts explained $87.7 \%$ of the variance for female salaries and $85.9 \%$ of the variance for male salaries.

Following this, the male equations were used to predict female salaries. The differences between the predicted and the actual salaries for females were used as indicators of discrimination, and became the basis of adjustments that were made in the salaries of female academics. These calculations suggested that corrections were needed for 76 of 83 females in Arts and Science $(X=\$ 3,974)$, all ten females in the Faculty of Commerce and Administration $(X=\$ 6,340)$, and 8 of 29 females in the Faculty of Fine Arts $(X=\$ 1,932)$. Finally, the report recommended that analyses should be repeated in five years, presumably with better data, when further adjustments may be made.

\section{Memorial University of Newfoundland (Schrank, 1985)}

Memorial University of Newfoundland had two studies of differences in salaries between males and females. In 1973, Schrank (1977) conducted the first study and noted that female faculty members were paid between $4.0 \%$ and $4.5 \%$ less than comparable male faculty members. This study estimated 11 regression equations that included various combinations of the following variables: faculty 
and department, academic rank, age, age squared, years of service at Memorial, years of service squared, years in current academic rank, years in current academic rank squared, research grants held, the number of books published since joining the Memorial faculty, journal articles published, administrative positions held, qualifications held (masters and doctorate), leaves, initial salary, and a series of interactions between gender and most of the other variables.

As a result of this study, the administration paid $\$ 64,000$ in adjustments to female faculty members (Schrank, 1985, p. 2). The faculty association assessed the adjustments and concluded that about one-half of the aggregated sex differences in salaries had been eliminated. In 1982, the president of Memorial agreed to support a second study using data gathered in 1982-83. This study was jointly sponsored by the administration of the university and the faculty association. Schrank was again commissioned to do this study, and with 3 assistants, gathered and coded the appropriate data over a 19 month period. At that time, 809 males and females $(16.3 \%$ ) held regular probationary and tenured appointments at Memorial University (Schrank, 1985).

Schrank (1985) identified 38 variables and groups of variables that should be included in the revised analyses. These variables and groups of variables included the following: academic discipline, department, faculty, sex, marital status, citizenship, year of birth, annual salary on appointment, 1982-83 salary, degrees, diplomas, years of university teaching, years of high school teaching, years of experience prior to becoming employed at Memorial, years of related experience, publications in journals, proceedings, and books, administrative experience, year of appointment, academic rank at appointment, the year tenure was awarded, years of sabbatical leave, years of leave without pay, grants received, publications after receiving an appointment at Memorial, membership on Royal Commissions, journal editorships, consulting experience, and a variety of other variables.

Stepwise least squares regression analyses were used to estimate 26 equations. Gender had a main effect in only one equation, but it had interaction effects in a number of the other equations. Schrank interprets the gender interaction effects as illustrating that females have been subjected to discrimination, not as a result of their gender per se, but as a result of their gender in combination with other characteristics such as their age, the faculty in which they are employed (e.g., Physical Education), and highest degrees, specifically for females holding only a bachelor's degree. At the same time, females with a Masters degree but no Ph.D. and females employed at the regional campus in Corner Brook had higher salaries than comparable males (Schrank, 1985: 34). 
Overall, Schrank suggested that the salary differential between females and males range between 1 and $4.6 \%$ of the average annual salaries of males.

\section{Queen's University (1991)}

Queen's most recent salary study (1991) was conducted by the Principal's Review Panel in response to provincial legislation on pay equity. As with all the other studies, this one also used multiple regression procedures to assess differences in salaries between male and female faculty members. This study is the only one that includes a variable reflecting the market conditions of different disciplines. In this respect, the committee noted that many salary decisions are determined by market-conditions that operate for faculty members in various departments and faculties; thus national market-conditions for the appropriate disciplines were incorporated into the analyses. The variable measuring market conditions was constructed from Statistics Canada calculations of average Canada-wide salaries for academics in age-specific discipline groups. Calculations were only conducted for the salaries of males, and these calculations were used to construct an index reflecting the national market conditions for each discipline for a variety of age groups.

In addition, this study is noteworthy for the effort the committee made at measuring experience. The committee constructed detailed guidelines on measuring experience and the Deans met to discuss these guidelines. This was to ensure that common university-wide procedures were followed. As a result, these guidelines were used by all Deans to assess each of their faculty members. The guidelines provided indicators for including non-university experience, teaching experiences that academics may have had in other institutions, and the time that academics may have had on reduced appointments. Age is not included in this study; presumably, the experience variable is a more relevant indicator of salary than age.

The issue of performance was also explicitly addressed in this study. Performance influences salary directly through merit awards and indirectly through promotion of academics to higher ranks. The Panel had been instructed to include academic rank as a variable in explaining differences in salaries between males and females. They considered using rank as a variable in their regression analyses, but following the advice of Allen (1984) that there may be a gender bias in promotions, they decided that academic rank was not an appropriate variable to include. In responding to the report of the Panel, the Principal of Queen's University noted that an earlier study of promotions had traced the difference in promotion patterns by gender to, among other factors, decisions by some females to restrict their careers for family reasons. This would suggest 
that promotion rates may differ by gender, but this difference need not necessarily reflect discrimination by the university.

Individual faculty members at Queen's are given merit scores as part of their annual performance review, and the Panel noted a problem with using these merit rankings, similar to the problem with using academic rank. The Panel had a seven-year merit average score for each faculty member, and the Panel argued that differences in average salaries between the genders must have arisen from either differences in initial salaries or differences in merit increases. As a result, a subgroup of the committee argued that it would be inappropriate to include merit in the analyses. Since the Panel was divided on the issue, results were provided with and without the merit variable included.

Single equation analyses were used, with sex as one of several exogenous variables. The dependent variable is the natural logarithm of nominal, marketadjusted, annual salary for each academic at Queen's. Two models were presented, with and without the merit variable included. When the merit variable was excluded, four independent variables were used: number of years of experience, number of years of experience squared, department affiliation, and gender. This model explains $75 \%$ of the variation in salaries and the coefficient for gender was -0.052 , which suggests that, on average, females were paid about $5.2 \%$ less than comparable males. When the merit variable was included with the other variables and an interaction term representing the merit variable times the number of years experience, the model explains $84 \%$ of the variation in salaries and the coefficient for gender was -0.035 . This suggests that females were paid about $3.5 \%$ less than comparable males. The interaction variable was used because the increases in salaries that academics received varied significantly with their years of experience.

In addition, the relationship was examined between gender and the merit variable. This analysis showed that merit scores were approximately $5 \%$ lower for females than for males with comparable years of experience. The Panel notes that the merit process needs further examination. Over the last several years, average merit awards did not differ by gender, but the seven-year averages did differ significantly by gender. The Panel recommended further study of this issue.

\section{Simon Fraser University (1991)}

A preliminary study at Simon Fraser University was completed in 1991, and used a different methodology than the other studies. This study was based on a series of two and three variable cross-tabular analyses. A pilot study using multiple regression analysis was discussed in the report, but no results from the 
regression analyses were presented. The pilot study recommended that the independent variables include publications, grants received, years since highest degree, experience, teaching ratings, and service ratings.

The Simon Fraser report begins by noting that before any variables were controlled, the average salary for females was $15 \%$ lower than the average salary for males. However, a number of factors can explain these differences, including differences between males and females in qualifications and experiences. As such, three independent variables were included in the analyses: qualifications, measured by whether a faculty member holds a Ph.D., market factors, and experience. Fewer females than males held doctorates $(82.6 \%$ versus $91.7 \%$ ) and faculty members, irrespective of their gender, were paid less, on average, if they did not have Ph.D.s.

Instead of including 'holding a Ph.D.' as a variable, the committee restricted its analysis to only the academics with doctorates. In addition, the committee attempted to adjust for differences in market conditions of different disciplines. First, it distinguished between market and non-market disciplines. Market disciplines include Engineering Science, Computing Science, Criminology, and Business. Presumably, there was a market value outside a university for academics in these disciplines. In market disciplines, average salaries were $7.6 \%$ lower for females than for males before other variables are controlled. In non-market disciplines, average salaries were $14.6 \%$ lower for females than for males. As noted previously, these differences apply only to faculty members who held doctorates, and thus correct for only one significant determinant of average salaries. Second, as an alternative procedure, the committee attempted to separate faculty members with and without market values in their salaries. The report did not indicate how these market values were determined. Nevertheless, after identifying faculty members according to this criterion, it was found that females with market value outside universities received, on average, $1.3 \%$ less in salaries than males, while for faculty members who did not have salaries that contain market values, females received, on average, $15.1 \%$ less than males.

Third, the study included a proxy for experience. Without actual data on experience, the number of years since being awarded a Ph.D. was used. Simple plots of nominal salaries across number of years since being awarded a Ph.D. indicated that experience was rewarded at a higher rate for males than for females, and as a result, differences in salaries between the genders increased with years of experience. The simple plots also suggested that females were paid more than males for the first few years of their employment. The study 
estimated salary differentials by estimating the average salaries for females using a cross-tabular analysis of nominal salaries of males by number of years since they were awarded Ph.D.s. Overall, these calculations suggested that females were paid $7.5 \%$ less than males if their salaries did not include market values, and $5.7 \%$ less if their salaries included market values.

The study also examined rank and noted that there is a significant difference in the salaries of males and females for full professors. At this level, the average salary for females was approximately $10 \%$ lower than the average salary for males, although males had, on average, four more years of experience than females. All faculty members (except one) who were originally hired at the rank of full professor were males, and $50 \%$ of these people were hired before 1975 when Simon Fraser University was hiring full professors as Heads of Departments and Deans of Faculties. A variable measuring administrative responsibilities was not used in the analyses to explain differences in salaries between the genders.

At the assistant and associate academic ranks, the difference in salaries between males and females was less pronounced, and in some categories the average salary of females was higher than the average salary of males. However, the average female assistant professor had two years more of experience than the average male assistant professor. At Simon Fraser University, a greater proportion of female academics were at the assistant and associate levels than were at the full professor level. The different distribution of males and females, across ranks, explained some of the differences in their salaries. The report suggested that females were promoted more slowly than males, and if females had been promoted at the same rate as males, there would be five additional female associate professors and eight additional female full professors. The report noted that there was no significant difference in the salary progress increments by gender and that additional analyses were required to determine if the genders differed in their rates of promotion.

The committee also provided estimates of the differences in salaries for males and females at the levels of assistant and associate professors. Since not all academics at Simon Fraser University were hired directly after completing their Ph.D.s, an estimate was made of how much they were paid per year after they completed their Ph.D.s. The committee reasoned that the initial salary of academics is largely determined by the number of years of previous experience. Following this reasoning, males at the assistant professor level were paid $\$ 325$ more than females for each year of experience they had, and at the associate professor level, males were paid $\$ 944$ more than females for each year of experience. 


\section{University of Manitoba (1992)}

The University of Manitoba report was completed in March, 1992, and used multiple regression analyses to assess differences in salaries for all male and female faculty members who belong to the University of Manitoba Faculty Association (UMFA). The gross average salary of females, $\$ 54,522$, was substantially lower than the gross average salary of males, $\$ 71,551$. However, the committee acknowledged that there were considerable differences between the genders that account for differences in salaries: females were considerably younger than males; they had less experience; and fewer of them had Ph.D.s. The committee attempted to control for these variables in the regression analyses, but no other variables were considered. In particular, rank was excluded because, as the committee argued, "it is an inappropriate factor to include since much of the discrimination between men and women must occur in promotions." For the same reason, the committee argued that starting salaries should be excluded; starting salaries are also likely to be tainted by discrimination.

The equations for females and males, incorporating age, experience, and highest degree, explained 53 and $65 \%$ of the variance in salaries respectively. The equations for both males and females were statistically significant. The committee recognized that including more variables would probably improve the explanatory power of the equations, but the committee did not have enough time and resources to collect additional information. In addition, the committee was only responsible for suggesting a way to allocate $\$ 100,000$, a small proportion of the total amount they argued was needed to eliminate gender discrimination. A follow-up study was recommended.

On the basis of these three variables, the report provided estimates of the salaries that females would receive if they were comparable to males. Using this procedure, the committee estimated that discrimination against female faculty members was, on average, $\$ 4,791$ per female faculty member, a difference that represented approximately $8.8 \%$ of the average salary of males.

Separate analyses were conducted for librarians, although the results were less satisfactory because there were many fewer librarians than professors. Age, experience, and highest degree explained $56 \%$ of the variance in salaries for female librarians and only $38 \%$ of the variance in salaries for male librarians. Using the equation for the males, the committee estimated that discrimination against females averaged $\$ 3,749$ per female librarian.

All of these reports are important additions to the literature on salary discrimination. They represent attempts to address the issue and provide appropriate redress at the institution level. All five reports find some evidence for 
gender discrimination in salaries, although the specific approaches taken by the various committees were different. In this respect, they are consistent with the published literature, almost all of which finds evidence of salary discrimination against female faculty members. Furthermore, the size of the discrimination is in the range of the estimates that have been presented in the published literature. However, there are substantial differences in the approaches taken to estimate these results, and in the following section these approaches are considered more carefully to assess the strengths and weaknesses of the reports.

\section{A Critical Evaluation of the Reports}

In Canadian universities, unionization and the implementation of pay structures makes analyses of pay equity relatively easy. Initially, salaries are likely to vary because of differences in starting salaries, the progression of people through the ranks from lecturer or assistant professor to full professor, the time they spend in each rank, and their contribution in teaching, research, and service. Theoretically, at least, gender should not affect the salary structure of faculty members. Nevertheless, judgements are involved in many of the salary decisions that people make, and judgments may be influenced by discriminatory attitudes. Consequently, the discussion over how to estimate differences between the salaries of males and females is complicated by argument over whether the explanatory variables are themselves biased as a result of discrimination.

However, there are several legitimate reasons why initial salaries might vary, such as the department to which the academic has been appointed and the productive resources the individual brings to the department, including research grants, published articles and books, teaching competencies, and service to the community. Of course, gender is not one of these variables, and should not be used, even inadvertently, in determining salary. Even though gross differences exist, male and female academics may differ on variables other than gender, that may legitimately affect their salaries. As a result, their average salaries may not be the same.

\section{Experience and Seniority}

Experience directly affects salaries. Salaries rise, often in a non-linear fashion, the longer an academic is employed in a university (Barbezat and Hughes, 1990). If experience varies by gender, then part of the differences in salaries between males and females may be explained by differences in experience. Swartzman, Seligman, and McClelland (1992), for example, showed that after 
allowing for differences in the time that had passed since an academic was appointed as an Assistant Professor, female salaries rose from $87 \%$ to $94 \%$ of males salaries. In other words, when experience was included, the difference in average salaries between male and female academics was reduced from $13 \%$ to $6 \%$. So, the differences in experience between males and females may partly account for differences in salaries.

All five studies agreed that faculty members receive higher salaries as a result of their experience and seniority. There is, however, remarkable divergence in the ways that experience and seniority are assessed and the ways that they are included in the analyses. Three of the studies do not have data on the actual experiences of faculty members; they use proxy variables. The procedures used in these studies are not completely satisfactory. The committee at the University of Manitoba, for example, used two proxy variables as indicators of experience, age, and the number of years since faculty members received their final degrees. In doing this, they were following the CAUT report by Allen (1984), suggesting that while both of these variables contain gender biases, the biases offset each other. In other words, Allen (1984) claimed that age was probably biased in one direction because female faculty members tend to begin their academic careers later than males, while, for the same reason, number of years since receiving a final degree was biased in the opposite direction. Allen provided no empirical support for this argument. We know from other reports that these variables may be highly correlated with each other, making it difficult to determine the contribution of each variable to the explanation of salaries. This may be a problem if males and females differ on these variables, and the male equation is being used to predict the female salaries. Schrank (1977) reports that age, year of first degree, and year of last degree were so highly correlated that only one of these variables should be used to represent experience. In this respect, the studies do not provide information on the correlation between the proxies for experience; thus it is impossible to know if this is a problem.

The study conducted at Concordia University also included two experience variables, age and years since first full-time appointment. The reasoning of the committee was that age was a predictor of maximum possible career length while years since first full-time appointment was a predictor of minimum relevant career length. These two variables may be highly correlated and, as a result, they may suffer from the same problem as the two variables chosen by the committee at the University of Manitoba even though the variables are not the same. The category of years since first appointment is different from the category of number of years since the final degree, and the former essentially 
amounts to a measure of experience accumulated at the university where an academic is presently employed. The researchers for Concordia noted that their study was problematical because they did not have data on faculty-members' experience before their employment at Concordia; however, they did not attempt to solve this problem. Instead, they noted the difficulty in collecting the additional data. This is unfortunate. Having recognized that experience is probably the most important determinant of salary, and having also recognized that the existing measures of experience are inadequate, the Committee might have recommended that the university collect accurate information on the experiences academics had before their employment at Concordia. The study concluded with a general recommendation that better data should be collected before a follow-up study is undertaken.

In this regard, the studies at both Memorial and Queen's universities are noteworthy. Besides measuring the actual experiences that academics have had since joining Memorial University, Schrank's (1985) study included a large number of variables measuring prior experiences, including measures of prior teaching experience at both university and schools and the publications that academics had completed or published before joining the university. Each of these measures was entered as a single independent variable, resulting in a very large number of variables in the analyses. Undoubtedly, creating composite variables would have resulted in a better measure of prior experience. Nevertheless, several of the measures of prior experiences, including teaching experiences at other universities, experiences as sessional or part-time faculty members, and the time faculty members spent in related but non-teaching appointments, were significantly related to the salaries that Memorial University faculty members received. More significantly, the separate analyses for males and females indicated that there were gender differences in the effects of these variables on salaries (Schrank, 1985). This suggests that a more complete understanding of salary differences would result if variables that measure a great variety of the experiences were included in the analyses. In addition, this finding suggests that if these variables are not included in the analyses, the model is likely to be misspecified, and biased estimates of discrimination are likely to result.

The study at Queen's University is also noteworthy because it included a single composite variable for experience, constructed from each type of prior experience. A composite variable incorporates an explicit judgment about prior experience, and if these judgments are tainted by discrimination, the analyses are unlikely to identify gender bias in salaries. This is because the differences between males and females will be accounted for by the experience variable, 
which in this case would be a tainted measure. Unfortunately, we do not know if this is a problem with their procedures. Nevertheless, if this procedure of measuring experience is fair, it ensures consistent weighting of prior experience for both males and females. In addition, if the experience variable is fair for both males and females, and if it is included in the analysis, it would help in estimating gender discrimination that is independent of prior experience.

The detailed guidelines provided to Deans to assess the prior experiences of faculty members indicate the difficulty they had in assessing the variety of experiences that academics have which may be related to both their gender and their salaries. The considerable effort of the committee to define and measure relevant prior experiences need not be repeated in future studies; the data exist for present faculty members. A single variable measuring prior experience is much easier to understand and interpret than the large number of variables that were used in the Memorial University study. Furthermore, the guidelines that have been developed to measure these variables can be used to update the data set and to ensure that new faculty members are treated fairly. Other universities could benefit from using a similar strategy for measuring the prior experiences of their faculty members.

A final problem with the experience variable is that, no matter how it is measured, it is likely to be non-linear; university salary structures tend to flatten out at the top of the experience scale. In other words, the financial returns for experience decline over an academic career. In this respect, the study at Memorial University showed that the non-linear age variable, as a proxy for experience, was an important indicator of gender discrimination. The study at the University of Manitoba also included non-linear terms for both experience variables, age, and years since completing final degree. Nevertheless, the studies from Concordia University and Queen's University do not include nonlinear terms for experience. A graphical representation of the relationship between experience and salary is presented in the Simon Fraser University study, but the analysis does not include a non-linear term. In these studies, there are no arguments presented to support the assumption that experience should be measured as a non-linear variable even though considerable evidence from the literature suggests that this is the case. There is, however, more to the relationship between salaries and experience than longevity alone.

\section{Administrative Experience}

An additional factor, that is related to experience, is whether an academic has held an administrative position. Experience as an administrator tends to increase the salaries of academics (Becker and Goodman, 1991). Again, there 
are significant differences between the genders on this variable. As readers may expect, the percentage of females who have administrative experience is much smaller than the percentage of males. We are not arguing that the appointment of academic administrators is or is not biased. Our point is that even if universities increase the percentage of females who currently hold administrative positions, there will still exist an effect of past administrative experiences on salaries.

In the past, administrators often received permanent increases in their salaries. Some researchers point out that the unequal representation of females in administrative positions is a result of discrimination. Consequently, these researchers often argue that administrative experience should not be included as an explanation of differences in average salaries between academics. Even if discrimination can help explain differences between male and female academics in their administrative experiences, it is not the only variables that may explain such differences. Researchers cannot disregard the possibility that administrative appointments may also result from an academic's interest in administrative work. As a result, attributing all the differences in administrative experience to discrimination may overstate the case. Whether it does so is an empirical issue. The published literature presents conflicting results. Barbezat and Hughes (1990) include administrative experience and estimate gender discrimination at 6.7\%, while Raymond, Sesnowitz and Williams (1990) exclude it and estimate gender discrimination at $3 \%$. The five Canadian reports differ in the way that administrative experience is treated. The report from Memorial University is the only one that incorporates administrative experience into the analyses, and it shows that administrative experience had a positive impact on salaries.

In recent years, it has been common for administrative stipends to be relinquished when the appointments are concluded. Consequently, the gender bias resulting from administrative experiences is between faculty who held administrative positions some years ago and both male and female academics who never held such positions. Unless a variable measuring administrative experience is included in the analyses, those who never held administrative positions will appear to be underpaid. In most cases, this will include virtually all females but it will also include a substantial number of males, particularly younger males. If a variable that measures administrative experience is not included in the analyses, then the average salary of males is increased. This results because a number of highly paid males who previously held administrative positions have been included with other males who have never held administrative positions and have relatively lower salaries. Thus, by not including a variable that 
measures administrative experience in their analyses, researchers ensure that the effects of gender will be larger than would otherwise be the case.

This problem can be addressed by excluding academics who have been administrators from the analyses. This procedure is recommended by Becker and Goodman (1991), and is an appropriate procedure when there are relatively few of these academics and when they are overpaid relative to other academics with similar characteristics.

\section{Qualifications}

Qualifications also affect salaries, particularly initial salaries. Formby, Gunther and Sakano (1993) showed that the presence of an appropriate highest degree can affect salary between 4 and 7 percent. The presence or absence of a Ph.D., as the highest degree, is also significant (Becker and Goodman, 1991). After controlling for the presence of an appropriate final degree, as well as a number of demographic, productivity, and university characteristics, Formby, et al. (1993) concluded that there were no differences in the beginning salaries of male and female academics. Even if it is generally true that initial salaries are equal for equally qualified males and females, this does not mean that current salary structures are free of gender discrimination. It does suggest, however, that discrimination may apply to females who were hired some years ago and not necessarily to females who have been hired recently.

Of the five studies we reviewed, only the Queen's University study did not include a variable reflecting differences in the qualifications of faculty members. No reasons were given for this decision; it may be that virtually all academics at Queen's had relevant qualifications. In other words, there may have been too little variation for the qualifications variable to add anything to the analysis. At Simon Fraser University, on the other hand, there was a significant difference in the proportion of female faculty members with completed doctorates $(82.6 \%)$ in comparison with males $(91.7 \%)$. As a result, the committee at Simon Fraser limited their analysis to those academics with completed doctorates. This procedure reduced the unexplained difference in salaries between genders by approximately 12 percent. In other words, about $12 \%$ of the differences in salaries between males and females could be explained by differences in qualifications.

The other three studies all included a qualification variable. Qualifications can vary across a number of dimensions, including the number of degrees, their level, and their type, which may differ across disciplines. The University of Manitoba included a dummy variable for whether faculty members had completed Ph.D.s. This procedure is adequate for many disciplines, but in some 
professional schools, professional qualifications and not Ph.D.s are the highest appropriate qualifications. The studies at both Concordia University and Memorial University included measures of qualifications besides whether academics held a Ph.D. The committee at Concordia identified the most appropriate qualification for each faculty member in each discipline, and included this as a dummy variable. The researchers at Memorial identified a number of qualification variables, including Bachelor's, Master's, Doctorates, and professional qualifications for Engineers and Medical Doctors. Unfortunately, no attempt was made to identify whether the qualifications were appropriate for the discipline in which the faculty member worked. Consequently, the results of the analyses are often confusing. The results of one analysis, for example, suggest that females, who have Bachelor's degrees as their highest qualifications, are underpaid compared to other faculty members. In another analysis no effect of discrimination is observed for females who only hold Bachelors' degrees. Overall, we think the Memorial University study attempted to measure too many variables with too much detail, which can often result in estimated effects that are not consistent across a number of similar analyses.

Universities usually have information on the appropriate qualifications of their faculty members. Curriculum vitae for each faculty member, containing individual qualifications, is filed with the Deans of the various Faculties, and the Deans could easily designate the appropriate highest degree for the discipline within which each faculty member works. It may require time and effort to compile the information on each faculty member, but qualifications are an important determinant of salaries, and qualifications need to be included in analyses of differences in salaries.

\section{Market Variables}

One important difference in salaries can be noted in the disciplines in which males and females are hired. Market conditions, external to the university, affect salaries for different disciplines. Differences in these market conditions can affect the overall measure of salary differences among comparable individuals. For example, higher salaries for females in some disciplines, such as education, will partly offset lower salaries in other disciplines, such as health, making differences in salaries appear inappropriately small. The reverse can also occur. The point is that differences in salaries between comparably qualified males and females will be biased unless differences in market conditions are included in the analysis.

Four of the five studies included variables that measured market differences in the salaries of academics. The University of Manitoba study was the only 
exception, and the committee did not present any reasons for omitting this variable. There are a number of ways that market values can be measured, including using a number of variables representing different disciplines (see Guppy, 1989), using average salaries in comparable institutions for comparable ranks and tenure (Becker and Goodman, 1991), and using average departmental salary (Swartzman et al., 1992). All of these are ways of coding market variability for different disciplines. Not surprisingly, the four studies that used market value as a variable, used different ways of estimating its effect.

The committee at Concordia University estimated separate equations for different faculties, a procedure that ensures that differences in the market condition for different faculties are not attributed to gender. The researchers at Memorial University used a procedure similar to Guppy's (1989), but the variable is measured with considerably more detail. The advantage of the procedures used at Memorial is that it allows the researchers to examine gender differences by faculty, and the empirical results show that there were substantial differences in the salaries of comparable males and females in one faculty. This procedure recognizes that gender discrimination may not be prevalent in all departments and faculties, but it may be specific to certain departments and faculties. The study at Simon Fraser University divided the departments into market and non-market disciplines, a definition that may be useful internally but is less meaningful to outside observers. As an alternative procedure, the committee divided faculty members into two groups, regardless of their disciplines: those who had salaries that contained a market differential, and those who did not. Again, there is no discussion of how market values were determined. This is unfortunate because the variable assessing market differentials was a significant factor in explaining differences in average salary by gender. For faculty members with a market value included in their salaries, males were paid, on average, $1.3 \%$ more than females, while for faculty without a market value, males were paid, on average, $15.1 \%$ more than females. These results may suggest that competition constrains organizations from discriminating against females, or it may suggest that other unrelated factors account for the differences between the salaries of males and females who have little market value outside the university system.

The committee at Queen's University made considerable effort to include market differentials by discipline and by age. The salary data, for both females and males, were adjusted for market differences, using average national salaries for males with specific age and discipline configurations. This is an excellent procedure since it recognizes that labour markets are considerably more complicated than discipline markets. The data were calculated by Statistics Canada on 
a cost recovery basis. Other universities could follow a similar procedure. The available studies suggest that a market variable is an important factor in explaining salary differentials. It is possible to include such a variable, and doing so would increase our confidence in the estimates that they provide of gender discrimination.

\section{Productivity Variables}

Productivity also influences salaries and individual academics differ in their productive contribution to universities. Academics are expected to conduct research and engage in scholarly activities, teach, and provide voluntary service to their university and to society. Furthermore, these components of productivity are included in the collective agreements between faculty associations and universities, and they are the basis for evaluating faculty members for tenure and promotion.

Research and scholarly productivity are usually measured by the number of books and articles an academic has published as well as by the number, and value, of research grants that have been obtained. Citations have also been used as a measure of the quality of academic research (Hamermesh, Johnson, \& Weisbrod, 1982; Long, Allison, \& McGinnis, 1993). The analyses of differences in salaries for academics indicate that research and scholarly productivity results in higher salaries (Barbezat \& Hughes, 1990; Hamermesh et al., 1982; Raymond et al., 1990). In this respect, there is evidence that the type of research and scholarship that academics publish varies by gender (Broder, 1993). In addition, there is also evidence that research and scholarly publications are rewarded differently for males and females (Barbezat \& Hughes, 1990; Weiler, 1990). Because academics differ in research and scholarly productivity, and because virtually all collective agreements acknowledge that this is a major determinant of promotion, it must be included in analyses of differential salaries for males and females.

It is more difficult to measure the contributions that academics make to teaching and service than their contributions to research and scholarship. Some studies have included the number and value of instructional grants as an indicator of teaching ability (see Raymond et al., 1990), but this a rather inexact measure especially since relatively few people have received instructional grants. Nevertheless, we have argued that teaching and service are both important determinants of tenure, promotion, and salaries. Consequently, it is necessary to include measures of these variables in assessing differences in salaries between male and female academics. 
Surprisingly, only the reports from Memorial University and Queen's University included measures of research productivity. At Queen's, the argument about including a productivity variable was a dissenting opinion by a minority of the committee. The report at Memorial included measures of journal articles and books published, conference papers, reviews and abstracts, as well as artistic works. The number and amounts of research grants that faculty members received were also included. There were even separate variables to identify faculty who received professional recognition such as appointment as members of a Royal Commission or the Royal Society, as journal editors, or to government boards. If anything, there is such an abundance of variables that there may be little variation in some of them. In this case, it may have been better to create composite variables measuring productivity. Nevertheless, none of the variables that measured the recognition academics received (e.g., appointment to a Royal Commission) had significant effects on salaries, but several of the publication variables made significant contributions to salaries. These analyses show that research and scholarly productivity is an important determinant of salary.

The Queen's University study raises a different issue. The inclusion of a productivity variable increased the explained variance from $75 \%$ to $84 \%$. This indicated that actual productivity rankings are a significant factor in explaining observed differences in salaries. Some of these differences were appropriate, but the majority opinion in the report argued that inappropriate salary differences must be due, in part, to differences in annual merit awards. The majority argue that this makes it difficult to justify using merit awards as a proxy for research and scholarly performance. Part of the problem may be that the productivity variable used by the committee was the same variable that was used, year-by-year, for merit increases. Presumably, research and scholarly performance affect salaries, and the dispute is over how to measure scholarly performance and how to include it in analysis of the relationship between gender and salary. The committee recognized this by recommending salary adjustments to female faculty members that are the average $(4.35 \%)$ of the estimated discrimination with $(3.5 \%)$ and without $(5.2 \%)$ the productivity variable included the analysis. The measure of merit used at Queen's University is a subjective measure of merit that reflects the evaluator's (usually a Dean's) assessment of the faculty member's contribution, summarizing the objective measures of research and scholarly performance and the more subjective estimates of other contributions. A summary subjective measure, however, may contain a gender discrimination component, and that part should be properly attributed to gender itself. 
One alternative procedure is to use a limited set of objective measures of research and scholarly performances in the analyses. Presumably, decisions on publications and research grants are made outside the university, and consequently they do not reflect discrimination by the institution itself. Measures of teaching performances and evaluations of service may be available or relatively easily constructed. It fact, some of the ambivalence that the various committees had about the productivity variables may have more to do with research and scholarly productivity, which have been easier to measure objectively, than with teaching and service, which have been more difficult to measure objectively. If females are better teachers and make greater contributions to service than males, as some literature suggests, then limiting the assessment of productivity to objective measures of research and scholarly performances may unduly bias the results in favour of males.

In the face of this difficult problem, Simon Fraser University recommended a pilot project using a four-point scale for measuring research and scholarship, teaching, and service. The criticism of this procedure is that the assessments are still subjective, and may be based, to some degree, on gender discrimination. However, this approach is probably better than not including assessments of these variables in the analyses. In fact, the literature suggests that including performance variables decreases the estimate effects of discrimination against female faculty members by as much as one-third (Barbezat, 1987). As such, analyses of gender discrimination that do not include measures of productivity are probably misspecified.

\section{Academic Ranks}

The category of academic rank pertains to professorial rank and the effect this has on salaries. Academic rank influences salary directly and females are not evenly distributed throughout the professorial ranks. Females represent only 12 percent of the professors who are older than 50 years of age, and they represent 28 percent of the professors who are under 40 years of age (Statistics Canada, $\# 81-241$, Table 7). There is a relatively slow turnover among university professors, and full professors, who were often hired more than twenty-five years ago, are much more likely to be males than females. Because salary is directly related to academic rank, and rank, in turn, is related to the time professors have been employed, the average salary of females is generally lower than the average salary of males (Statistics Canada, \#81-241, Table 7).

In studies of academic salaries, rank is a consistent and positive explanatory variable. In the traditional single equation approach to estimating gender discrimination, rank may be a biased variable, in that gender may be one of the 
factors that explain rank. A separate equation predicting rank may be more appropriate if the biasing effect of rank is to be controlled. Some recent studies include separate equations for rank. Weiler (1990), for example, found that even after allowing for a number of variables measuring experience, market, research, and qualifications, the rank distribution for females is lower than would be expected. Broder (1993) employs a similar procedure but found that the average female had a salary that is slightly, but not statistically significant, lower than the average male. The implication is that including rank in the analyses of salary differences may mask a portion of salary discrimination. Weiler (1990) suggests a procedure for decomposing the contribution discrimination has on rank and including it as an unbiased measure of differences in salaries between males and females. As with salaries, rank is not solely determined by gender; variables measuring merit also count. These indicators may be included directly through productivity variables or indirectly through the rank variable. If both types of variables are excluded, then variables that are known to be significant determinants of salaries are excluded from the model, and the results are probably biased. Barbezat (1987) found that including either rank or publications reduced the estimate of discrimination by approximately one-third. In essence, excluding rank from the model because it may be biased is not adequate.

One alternative to omitting rank entirely is to test whether the predicted promotion rate for females is the same as the predicted rate for males. This is the procedure followed by Swartzman et al. (1992) at the University of Western Ontario. These researchers predicted rank using age, highest degree, years since highest degree, years since first appointed as an assistant professor, and the average departmental salary as a control for market variation. They discovered that both females and males were equally likely to be promoted to the rank of associate professor. Having established that rank was not tainted by discrimination, these researchers incorporated rank into the analyses of salary differentials between males and females. They found that it is the third most important variable in explaining the variation in salaries. Specifically, the three most important variables included, years since first appointed as an assistant professor, average department salary, and rank.

The five reports reviewed in this paper differed in their treatment of rank. Rank was included in the study at Memorial University (Schrank, 1985), but excluded at the other four universities. Schrank had provided a detailed examination of the factors that predict rank in a number of equations, and gender was an important variable. Females with modest research output were more likely 
than comparable males to be promoted to the rank of associate professor, but they were less likely than males to be promoted to full professor, especially if they were research stars with substantial publications. In other words, Schrank (1985) showed that discrimination resulted from the interaction of gender, rank, and productivity. Overall, Schrank (1985) suggested that excluding rank and initial salary, gender discrimination was about $4.8 \%$, whereas including rank along with these other variables reduced the effect of discrimination to about $3.8 \%$.

Unfortunately, the other reports have not included rank because the committees accepted Allen's (1984) suggestion that it is tainted by gender discrimination. As a result, compensating females on the basis of analysis that excludes rank essentially amounts to paying the hypothetical average female as if she had been promoted at the same rate as the hypothetical average male. If females have been inappropriately denied promotion, and this is not addressed, then when the study is repeated in the future (as many of the reports recommend), gender discrimination will again appear in the salary structure even if considerable money had been spent on adjusting the salaries. If universities continually make salary adjustments without considering rank, then they compensate female faculty members as if they had attained a higher rank, but without the other advantages of promotion.

\section{Model Significance}

Now that the five studies have been reviewed, we can ask: How well have the models in these reports explained differences in salaries between male and female faculty members at their respective universities? The answer to this question is important because discrimination is not measured directly but is estimated using residuals where discrimination is assumed to be the difference in the salaries of males and females that have not been explained by the variables included in the analyses. In other words, none of these studies have direct measures of discrimination, but are estimating the effects of discrimination from residual differences after other relevant variables have been controlled. As a result, the estimates of discrimination may be biased if all other relevant variables have not been controlled. This specification bias could be in either direction, but in four of the studies we review (the exception is Memorial University) the bias is probably upward. The implication is that estimates of discrimination which use this procedure probably represent upper bound estimates of the discrimination in salary structures. In other words, when relevant variables are omitted from the models, the estimates of discrimination are likely higher than they would be if these relevant variables were included in the analyses. On this 
ground, there is value in the approach used at Memorial University of including every conceivable variable that may explain variation in salaries and then interpreting the trends in the residuals that indicate the gender discrimination that might exist.

The five reports do reasonably well at explaining overall salary variation, particularly since they have had to deal with the problems outlined above. The report from Memorial University explained more than $90 \%$ of the variation in all salaries, and similar results were obtained for the variation in salaries for males and females separately when rank was included as a variable. Without including rank and initial salary in the equations, the explained variance in present salary dropped substantially to about $73 \%$. The study from Queen's University explained $75 \%$ of the variance in salaries with the merit variable excluded and $84 \%$ when the merit variable was included. The study from Concordia University explained between $86 \%$ and $88 \%$ of the variance in salaries in one small Faculty but only between $64 \%$ and $77 \%$ of the variance in salaries for males and females in the Faculty of Arts and Science where most of the faculty members were employed. The study at the University of Manitoba explained only $65 \%$ of the variation in the salaries of male faculty members and $53 \%$ of the variation in the salaries of female faculty members. Memorial University and Queen's University explained more of the overall variation than Concordia University and the University of Manitoba. The increase in explained variance in salaries at Queen's University was probably the result of the particular care with which the researchers defined and measured the productivity variables. This suggests that the results for Manitoba and Concordia would be improved if they included productivity variables in their models, and consequently the differences between males and females would be reduced.

To this point, we have identified a number of variables as possible determinants of differences in salaries between males and females. Even so, there are likely to be a number of specific factors corresponding to the special circumstances of different people that affect their salaries. If these factors are essentially random, they could be called luck, and they will have no effect on estimating differences in salaries between males and females. Some faculty members are more or less lucky than others; they have different salaries than others with similar objective characteristics, and only a case by case examination might disclose the unique factors involved. Consequently, no model will completely explain all the observed variation in existing salaries. However, the studies should explain enough of the variation that other variables that have been omitted do not bias the results. 
Almost all variables used in these studies may be tainted by discrimination. Nevertheless, this need not prevent researchers from including measures of these variables. If the variables are tainted, the bias in the analysis that is introduced by including them may even be less than the bias in the analysis that results from their exclusion. This results because there are two factors involved: a bias introduced among individuals who are otherwise similarly qualified, but differ on this variable, and a bias resulting from gender.

\section{Conclusion}

The issue of salary discrimination on the basis of gender is important and universities are beginning to address this. Universities have traditionally been in the vanguard of progressive thought; and thus it is expected that they would be active in attempting to ensure that their salary structures are fairly applied to all faculty members. All five reports provided estimates of gender discrimination in their salary structures. The range of discrimination in salaries was from $3 \%$ to $8 \%$, which represents a substantial amount of money when it is translated into the actual cost to the university and to individual faculty members. The lower estimates of discrimination come from studies that have included variables measuring productivity while the higher estimates come from studies that have not included variables measuring productivity. Considering that productivity measures are included in the collective agreements of all five of these universities, and are the basis for tenure and promotion decisions, the models are probably misspecified if they do not include measures of productivity. This probably results in higher estimates of the effects of discrimination than would be the case if productivity measures were included in the models.

Nevertheless, universities will require substantial financial commitments to compensate individuals who have suffered discrimination. If universities decide not to include productivity variables in the model or if they decide to compensate everyone, males and females, who have suffered discrimination, then the compensation will be higher than if they decide to include productivity variables and to compensate only female academics. In any event, the sooner the corrections are made, the cheaper it will be for the universities to eliminate inequities. Shrank noted (1985, p. 67) that payments made after his 1973-74 study permanently corrected the inequities for the females who received payments.

In addition, the studies at Queen's and Memorial universities had considerable success in measuring appropriate productivity variables and estimating the cost of discrimination against female faculty members. The study at Memorial 
University was particularly noteworthy for the way the variables were measured and the number of variables included in the analyses. These variables were explicitly designed to incorporate much of the unique circumstances that apply to a diverse faculty. This is the reason that the study at Memorial University explained the highest percentage of the variation in salaries of any study we surveyed. The study at Queen's University is also noteworthy for the effort the researchers made to incorporate market conditions, measuring experience along a variety of dimensions, and the way merit was included in the analyses.

Without detracting from the intent of the other studies to address these issues as fairly as possible, they have been less successful in addressing some of these fundamental issues. The study at Simon Fraser University concluded with an excellent proposal for collecting better data and for further research, but it had inadequate documentation of the current research. The study at the University of Manitoba appeared to have followed the advice of CAUT (Allen, 1984) so closely that the model was probably misspecified. The research at Concordia University could be improved by developing measures of experience that reflect those items that were included in the collective agreement. In addition, it is unlikely that the salary structure at Concordia contained as much random variation as the results of the present study indicated.

There is a substantial amount of published research on pay equity. Consequently, it might be expected that a greater consensus would have emerged on how to conduct pay equity research in universities. In particular, it might be expected that universities would have developed and implemented procedures to measure the necessary variables accurately. At Queen's and Memorial universities, considerable effort was made in measuring the appropriate variables, although the approaches were quite different. At the other three universities, however, this has not yet been done. Perhaps the single most important recommendation to universities is to begin defining the relevant variables, measuring the variables properly, collecting the information, and estimating models that will give reasonable estimates of gender discrimination. It is ironic that some universities have not followed such procedures since these are the procedures that are the basis of good empirical research, an issue that universities are particularly concerned about. In addition, the issue is urgent; gender discrimination is a very important political issue in universities. This urgency can lead to inadequate measures of the amount of salary discrimination and to over-compensation of some people, an action likely to make other people, who are equally deserving, unhappy. Universities need to address this problem now. Delays in gathering the appropriate information result, ultimately, in delays in compensating those academics who deserve compensation. 
At present, there appears to be some consensus developing in the published literature about how to conduct pay equity research. It is necessary, for example, to include whether academics are tenured and/or promoted, as these variables are defined in the various collective agreements. In addition, it is important to include more than two or three independent variables. Furthermore, there now seems to be a consensus to use multiple regression analyses as the appropriate research methodology. Moreover, the research literature suggests that single equation models, that are still widely used by researchers and adopted by most of the studies we have reviewed, are probably inadequate.

The diversity of the methodological procedures used in these five studies is a credit to the creativity of the committees, but it is a disservice to the scientific integrity of the procedures and the issue. It may be appropriate for a national organization, such as CAUT and AAUC, to take up the challenge and outline the procedures that should be used in both assessing and compensating those who have suffered from discrimination. Additionally, more reports of gender discrimination can be submitted to journals for publication, ensuring that universities apply the same criteria to their own issues that academic faculty apply to their own research.

Our criticisms should not be taken to imply that no discrimination exists. All the studies find that some discrimination exists, and this is consistent with the published literature. Furthermore, the estimates are in the range of the estimates that have been published in research journals. Our critique should be interpreted as a call for more care in conducting these studies. Estimates that are as accurate as possible ensure that compensation accrues to those who truly deserve it, and that the procedures and the outcomes have wide acceptance in the university community.

\section{References}

Allen, J. (1984). Manual for the determination of academic salary discrimination Against Women. Ottawa, Canadian Association of University Teachers.

Barbezat, D. A. (1987). Salary differentials by sex in the academic labour market. The Journal of Human Resources, 22(3), 422-428.

Barbezat, D. A., \& Hughes, J. W. (1990). Sex discrimination in labour markets: The role of statistical evidence: Comment. The American Economic Review, 80(1), 277-286.

Becker, W., \& Goodman, R. (1991). The semilogarithmic earnings equation and its use in assessing salary discrimination in academe. Economics of Education Review, 10(4), 323-332.

Broder, I. E. (1993). Professional achievements and genderd differences among academic economists. Economic Inquiry, 3I(1), 116-127. 
Concordia University (1991). Joint pay equity study report. Montreal, P.Q.

Formby, J. P., Gunther, W. D., \& Sakano, R. (1993). Entry level salaries of academic economists: Does gender or age matter? Economic Inquiry, 3I(1), 128-138.

Guppy, N. (1989). Pay equity in Canadian universities, 1972-73 and 1985-86. Canadian Review of Sociology and Anthropology, 26(5), 743-758.

Hammermesh, D, S., Johnson, G. E., \& Weisbrod, B. (1982). Scholarship, citations and salaries: Economic rewards in economics. Southern Economic Journal, 49(2), 472-481.

Long, J. S., Allison, P. D., \& McGinnis, R. (1993). Rank advancement in academic careers: Sex differences and the effects of productivity. American Sociological Review, 58, 703-722.

Queen's University. (1991). Report of the principal's panel to review faculty women's salaries. Kingston, Ontario.

Raymond, R. D., Sesnowitz, M. L., \& Williams, D. R. (1990). The contribution of regression analysis to the elimination of gender based wage discrimination in academia: A simulation. Economics of Education Review, 9(3), 197-207.

Schrank, W. E. (1977). Sex discrimination in faculty salaries: A case study. Canadian Journal of Economics, 10(3), 411-433.

Schrank, W. E. (1985). Sex discrimination in faculty salaries at Memorial University: A decade later. A report submitted to the President of Memorial University and the Executive Committee of the Memorial University of Newfoundland Faculty Association. St. John's Newfoundland: Memorial University.

Simon Fraser University (1991). Salary equity study committee report. Burnaby, B.C.

Statistics Canada. (various years).Teachers in universities. Catalogue \#81-241. Ottawa, ON: Minister of Supply and Services Canada.

Swartzman, L. C., Seligman, C., \& McClelland, W. J. (1992). Detecting gender discrimination in university salaries: A case study." The Canadian Journal of Higher Education, 22(1), 1-13.

University of Manitoba (1992). Final report: Joint University of Manitoba/University of Manitoba Faculty Association Committee on systemic differences in salaries between female and male academic staff. Winnipeg, Manitoba.

Weiler, W. C. (1990). Integrating rank differences into a model of male-female faculty salary discrimination. Quarterly Review of Economics and Business, 30(1), 3-15. 